\title{
NORTH-SOUTH ENVIRONMENTAL DEBATE: STRATEGIC PRICE DISTORTIONS AND CAPITAL FLOWS
}

\author{
Roberto Burguet* \\ Institute for Economic Analysis, Universitat Autònoma de Barcelona
}

\section{Jaume Sempere}

Centro de Estudios Económicos, El Colegio de México, A. C.

(Received 29 January, 2003, accepted $20 \mathrm{March}$, 2003)

\begin{abstract}
In our model, Northern governments have an incentive to set weak environmental regulations in order to increase domestic productivity and, thereafter, to increase the price of their capital exports. We investigate the effect of this distortion on the incentives for environmental protection in the South. Under reasonable assumptions, the South responds by lowering environmental protection. Thus, strategic price distortions lead to a globally dirtier environment.

\section{Resumen}

En nuestro modelo, los gobiernos del norte tienen un incentivo para establecer regulaciones ambientales débiles, con el fin de aumentar su productividad y el precio de sus capitales de exportación. Nosotros investigamos el efecto de esta distorsión sobre los incentivos para la protección del medio ambiente en el Sur. Bajo ciertas condiciones, el Sur responde con una disminución en la protección del medio ambiente. Por lo tanto, las distorsiones estratégicas de precios conducen a un ambiente globalmente más sucio.
\end{abstract}

JEL classification: $L 51, Q 20$

Keywords: Environmental regulations, North and South economies

* Centro de Estudios Económicos, El Colegio de México, A. C., Camino al Ajusco 20, 10740, México, D. F., Telephone (52) 54493000, E-mail: jsempe@colmex.mx

The authors are grateful to the anonymous referees for their comments. 


\section{Introducción}

In economics, as in other areas of public debate, we have witnessed a rising interest on the effects of human activities on the environment. One of the issues under scrutiny is the incentive of governments to set the correct policies for environmental protection. Concern with the effects of international trade on these incentives, in particular, has been the origin of a large literature in economics. Thus, and led by practical concern in the wake of regional integration, we now understand not only the need for coordination between environmental policies when pollution is transboundary (see Markusen, 1975, and Hoel, 1997), but also the way trade incentives affect the strategic setting of environmental policies when governments try to win a competitive edge for their firms (see, for instance, Kennedy, 1994; Barrett, 1994; Burguet and Sempere, 1998; and, for an excellent survey, see especially Ulph, 1996), and the consequences of using environmental policies to influence the relative prices of mobile factors (Rauscher, 1997).

The present paper is a contribution to the discussion of the latter issue. In general, previous contributions assume some kind of market power by governments and/or firms. Then, large countries, whose environmental policies have an impact on international factor prices, tend to lower their level of environmental protection in order to increase the marginal productivity (and therefore the prices) of their abundant factors (see Rauscher, 1997). The main goal of this paper is to analyze the response of small countries to the incentives created by large countries. ${ }^{1}$

Thus, we present a model of perfect competition with two countries and environmental damage associated to production. In each country, firms make their investment and output plans taking (capital) prices and environmental regulations as given. Also, consumers make their savings and consumption plans taking the interest rate as given. The North is capital abundant in comparison with the South, and large in the international capital market.

As we mentioned above, the North has incentives to distort the international interest rate by allowing higher emission levels. A higher interest rate for the South implies higher costs, and also higher domestic savings. We are able to show that under very general, and plausible conditions the Southern goverment responds by setting weaker environmental protection. The most important of

1 Rauscher (1997) analyzes the effects of increasing emissions by a capital exporter country on pollution levels of a capital importer. He is interested on the equilibrium effect on pollution due to equilibrium changes in production, and consumption. However, we are interested in the strategic effect on environmental policies of the capital importer country. Our work is related to other papers which focus on international environmental competition. Ludema, and Wooton (1994) have also considered how environmental policies can be an instrument in altering relative prices, this time in traded goods. Markusen, Morey, and Olewiler (1995) study the competition between countries in attracting firms to their respective territories. One could think of their model as one of competition in quantities (employment, output), whereas our model focuses on the distortion of prices associated with market power in terms of national factors. Beladi; Chao, and Frasca (1999) analyze pollution taxes, and foreign investment quotas for a small developing country. 
these conditions is that Southern countries are "small" in the international factor markets. The other conditions are:

i) Domestic savings are not extremely sensitive to higher interest rates in the South.

ii) The productivity of capital in the South is not extremely sensitive to environmental regulation.

iii) The productivity of capital in the South is senșitive to the stock of capital itself.

The results outlined above are important for the North-South environmental debate. The North is seen as the big polluter. The South has been arguing that the North should cut its emissions before the South itself undertakes this task. What the present paper suggests is that there may be good reasons for this insistence, and also for the reluctance of the North to yield.

The rest of the paper is structured as follows. The next section presents the model. Section 3 then establishes the well known incentives of the North to manipulate factor prices. Section 4 analyzes our main concern: how Southern countries react to this manipulation with regard to their environmental policies. Some concluding remarks close the paper.

\section{The Model}

Consider a world of two countries, North and South, respectively, $n$ and $s .{ }^{2}$ In each of these countries there is a representative consumer. Time is divided in two periods: present (period 1) and future (period 2). There is only one good, which can be consumed or used as input (capitall) in future production.

\subsection{Consumer}

Consumer $i$, where $i=n, s$, cares about consumption in both period $1, C_{1}^{i}$, and period 2, $C_{2}^{i}$. Each consumer has initial resources $W^{i}$ that he/she can consume in the first period or save. The return on these savings adds to second period consumption. We will assume that the North is richer than the South in terms of the initial resources so $W^{n}>W^{s}$. Let $S^{i}$ denote savings by consumer $i$. Consumers also (inelastically) provide labor in the second period. The wage revenue also adds to second period consumption. We will assume that consumers are price takers, so that they take both wages and interest rate as given. In particular, when deciding how much to save, they do not take into account how these savings may affect their wages in period 2 .

Thus, we let the consumers' preferences be represented by the utility function $u^{i}\left(C_{1}^{i}, C_{2}^{i}, E^{i}\right)$, where $E^{i}$ is an index of environmental quality, which consumers take as given. We assume:

(A.1) $u^{i}\left(C_{1}^{i}, C_{2}^{i}, E^{i}\right)$ is twice differentiable, strictly quasiconcave, increasing in present, future consumption, and in $E^{i}$. Moreover, $u^{i}$ is separable in

2 Notice that we model the South as a single country. However our interpretation of the South is that it consists of a large number of countries that are small in the international markets, so that their governments do not have the power to change international prices through their policies. Modeling the South as a set of small countries would complicate unnecessarily the notation without changing the nature of our results. 
consumption, and environmental quality. Finally, $u^{i}$ is linear in $E^{i}$. Then, let

$$
u^{i}\left(C_{1}^{i}, C_{2}^{i}, E^{i}\right)=U^{i}\left(C_{1}^{i}, C_{2}^{i}\right)+E^{i}
$$

This last simplifying assumption means, in particular, that savings are independent of the environmental quality, for a fixed interest rate. Obviously, this assumption will make income effects disappear, such as those discussed in Copeland and Taylor (1997). This will allow us to concentrate on the effects of capital market distortions. The consumers' budget constraints when making their consumption, and savings plans are

$$
\begin{gathered}
C_{1}^{i}+S^{i} \leq W^{i}, \\
C_{2}^{i} \leq S^{i}(1+r)+w^{i} l^{i}+\pi^{i},
\end{gathered}
$$

where, $\pi^{i}$ represents the profits of firm $i$, which we assume is owned by local consumers. Utility maximization under these constraints, and price taking behavior results, as usual, in the equality of the intertemporal rate of substitution, and the gross return of savings,

$$
\frac{U_{1}^{i}}{U_{2}^{i}}=1+r
$$

As usual, substitution of this expression in the budget constraint defines each country's savings function $S^{i}(r) .{ }^{3}$ We also define $S^{T}(r)=S^{n}(r)+S^{s}(r)$ as the total savings function.

\subsection{Production}

There is a single firm in each country that produces the consumption good for the second period using capital and labor. Firms borrow their capital from consumers' savings. We assume that capital is perfectly mobile across borders, and also that firms are price takers in the capital market. Denote by $k_{i}^{j}$ the amount lent by consumer $i$ to the firm in the country $j$, for $i, j=n, s$. Then $S^{i}=k_{i}^{j}+k_{i}^{i}$.

Let $f^{i}$ represent the technology available to firm $i$. Then, output from firm $i$ is given by $f^{i}\left(l^{i}, k^{i}, E^{i}\right)$, where $l^{i}$ and $k^{i}=k_{i}^{i}+k_{j}^{i}$ are, respectively, the labor and capital used in production by firm (country) $i$. Production generates local pollution as a by-product. Thus, the higher the environmental quality, as measured by our quality index $E^{i}$, the lower the output that can be obtained by using the productive inputs, capital and labor. ${ }^{4}$

3 Notice that $r$ is the only argument of $S^{i}(r)$, whereas usually we would need to make this function to depend also on $w$. We can make this simplification because we have a representative consumer in each country who is also the owner of the firm in the corresponding country. Then, a change in the wage rate, that produces a change in consumer's wage revenue, is exactly balanced by the change in firm's profit, where labor appears as acost

4 Notice that we model pollution (or its complement environmental quality) as an argument of the production function as in Copeland and Taylor $(1994,1995,1997)$ or Hoel (1997). However in these models, pollution is a variable which is freely chosen by the firms. In this model, instead, it will be set by the governments and regarded as a parameter by the firms. 
We make the following functional assumptions:

(A.2) The production function is twice differentiable, concave, and also satisfies that $f_{3}^{i}<0$, and $f_{j 3}^{i} \leq 0 .{ }^{5}$

Here $f_{j}^{i}$ denotes the derivative of the production function with respect to the $j$ th argument, and $f_{j k}^{i}$ is the cross derivative of $f^{i}$ with respect to the $k$ th, and $j$ th arguments. Apart from the traditional diminishing marginal products, the idea behind the sign of the derivatives in (A.2) is that for each additional unit of labor and/or capital that is used in production, a part of it must be used to keep the environmental quality constant, and the better this environmental quality, the larger this part is.

Assumption (A.2) agrees with existing empirical evidence about the impact of environmental regulation on factor productivity. These studies show that plants with stricter regulations tend to have lower productivity levels, and slower productivity growth. ${ }^{6}$

Given price taking behavior by all agents, and free mobility of capital across borders; there will be a single interest rate, $r$, in the international capital market, which, when measured in terms of the consumption good, will be determined by equal productivity of capital. That is, equilibrium capital demand for each firm, $k^{i}\left(r, E^{i}\right)$, is determined by

$$
(1+r)=f_{2}^{n}\left(l^{n}, k^{n}, E^{n}\right)=f_{2}^{s}\left(l^{s}, k^{s}, E^{s}\right) .
$$

Labor, on the other hand, cannot be traded internationally and is supplied inelastically. Thus, any change in labor demand in each country will only result in changes in the domestic wage rate.

\subsection{Equilibrium}

Equations (1), and (2) plus the capital market equilibrium equation

$$
S^{T}(r)=k^{n}\left(r, E^{n}\right)+k^{s}\left(r, E^{s}\right)
$$

define savings and capital as functions of the interest rate, for given levels of environmental quality. Consumers of both countries will determine the total amount of savings $S^{n}$, and $S^{s}$. Equilíbrium conditions in capital markets will determine the allocation of these savings across countries $\left(k^{s}\right.$, and $\left.k^{n}\right)$, as a function of $E^{n}$ and $E^{s}$, given $l^{n}$ and $l^{s}$.

\section{Environmental Policies}

The last type of agent that we consider is the government. We assume that governments set their domestic environmental index $E^{i}$. This is the only policy

5 These assumptions are as in Rauscher (1997).

6 See Gollop, and Roberts (1983); Gray (1987); Barbera, and McConnell (1986); and Gray, and Shadbegian (1995) among others. For instance, Gray and Shadbegian's (1995) calculations using plant-level productivity data for three industries show that a plant with one dollar higher abatement costs tends to have the equivalent of 1.74 dollars lower productivity in paper, 1.35 lower in oil, and 3.28 lower in steel. 
instrument for the governments. This will be equivalent to having governments set environmental instruments (for instance, environmental taxes, emissions standards, etcetera), so that the desired level of environmental quality is attained. Also, we assume that the South is small in the international capital market, so that the Southern government takes the interest rate, $r$, as given.

\subsection{Non-Strategic Policies}

Let us first analyze what the savings, consumption, and environmental decisions would be in the absence of strategic country interaction. For that, we consider the "autarky" case, that is, the case in which each country is isolated from the other (no capital flows). In that case, the government would choose the level $E$ so as to maximize $u$, taking the decisions implied by equation (1) as given (for simplicity, in this subsection, we do not use the superindices corresponding to the countries). From the government point of view, $C_{1}=W-S(r)$, and $C_{2}=$ $f(l, S(r), E)$. Then, the first order condition that defines optimal environmental quality $E$ is:

$$
-U_{1} S^{\prime} \frac{\mathrm{d} r}{\mathrm{~d} E}+U_{2}\left[f_{2} S^{\prime} \frac{\mathrm{d} r}{\mathrm{~d} E}+f_{3}\right]+1=0
$$

By substituting this result in equation (1), and considering that under equilibrium conditions $f_{2}=(1+r)$, we may say that:

$$
U_{2} f_{3}+1=0 .
$$

This equation, together with equation (1), would then define the savings level, $S$, and environmental quality, $E$, (and therefore consumption too) under autarky. In particular, the level of $E$ would more than compensate for the positive effect that a less stringent environmental policy would have on the second period consumption through increased output $\left(U_{2} f_{3}\right)$ with the direct utility impact of a worse environment. The savings level $S$ would simply equate the marginal rate of substitution between consumption today and consumption tomorrow with the relative cost, that is, the productivity of capital. This "autarky solution" coincides with the one that would prevail under price (interest rate) taking behavior by the governments, except that the interest rate would then be common to both countries. The goal of the next subsection is to analyze the incentives introduced by the fact that the Northern government can affect the international interest rate by using its environmental policies.

\subsection{Strategic Behavior of the North}

Notice that the consumption by each consumer in the second period is now equal to the level of output in their country net of interest payments across borders. Thus,

$$
C_{2}^{i}=f^{i}\left(l^{i}, k^{i}, E^{i}\right)+(1+r)\left(k_{j}^{i}-k_{i}^{j}\right) .
$$

In equilibrium, only one country will be exporting capital. In general, the North will be a net exporter, with $k_{n}^{s}=S^{n}-k^{n}$, and $k_{s}^{n}=0 .{ }^{7}$ Then, the objective function of government $s$ is

$$
u^{s}\left(C_{1}^{s}, C_{2}^{s}, E^{s}\right)=U^{s}\left[W^{s}-S^{s}, f^{s}\left(l^{s}, k^{s}, E^{s}\right)-(1+r)\left(S^{n}-k^{n}\right)\right]+E^{s},
$$

7 This requires "relative" capital abundance. For instance, and for similar technologies, larger per capita savings in the North. 
where, we are taking into account the interest payments for the import of capital $\left(S^{n}-k^{n}\right)$ from $n$. Likewise, the objective function of $n$ 's government is

$$
u^{n}\left(C_{1}^{n}, C_{2}^{n}, E^{n}\right)=U^{n}\left[W^{n}-S^{n}, f^{n}\left(l^{n}, k^{n}, E^{n}\right)+(1+r)\left(S^{n}-k^{n}\right)\right]+E^{n} .
$$

Also, the South takes $r$ as given, whereas the North considers the effect of $E^{n}$ on $r$. Note that increases in the environmental quality in the North will have a negative effect on the interest rate. Indeed, differentiating equation (3) we have

$$
\frac{\mathrm{d} r}{\mathrm{~d} E^{n}}=\frac{\partial k^{n} / \partial E^{n}}{S^{T \prime}-\partial\left(k^{s}+k^{n}\right) / \partial r}
$$

where, we omit arguments of the functions for simplicity, and $S^{T^{\prime}}$ is the derivative of the total savings with respect to $r$ according to equation (1). Now, if we substitute for $\partial k^{n} / \partial E^{n}$, and $\partial\left(k^{s}+k^{n}\right) / \partial r$ (from equation (2)), we obtain

$$
\frac{\mathrm{d} r}{\mathrm{~d} E^{n}}=f_{23}^{n} G \frac{1}{1-S^{T^{\prime}} f_{22}^{n} G}<0,
$$

where

$$
G=\frac{f_{22}^{s}}{f_{22}^{s}+f_{22}^{n}} .
$$

The sign comes from the fact that $G>0, S^{T \prime}>0$, and $f_{22}^{i}, f_{23}^{n}<0$. The effect of $E^{s}$ on $r$ would have a similar expression, substituting the superscript $n$ for $s$, and vice versa. However, the South is a price taker, which means that the denominator is very large. This is the case if $S^{T \prime}$ is very large with respect to $f_{23}^{n}$. That is, if the South is indeed small in the international capital market. To summarize the above discussion, we have that: if a country (the North) is large in the capital market, an improvement in its environmental quality will lead to a fall in the interest rate (as Rauscher (1997) obtains for a different version of this model.)

The interpretation of this effect is simple. As country $i$ increases its environmental quality, the productivity of capital at home decreases by $f_{23}^{i}$. However, this creates an imbalance in the productivity of capital in both countries which will generate a flow of capital to the other country until the marginal productivities are equalized again, which in turn reduces the original impact. The measure of this capital flow has a direct component: recovering the balance would take a flow which is proportional to the relative responsiveness of the marginal productivity of capital in the foreign country to changes in capital which is measured by $G$. It also has an indirect component related to the response of savings (total capital supply) to the change in productivity conditions; a flow away from the country would increase the productivity of capital, thus increasing the total capital supply $S^{T}$. Then, the total capital flow away from the country (measured in terms of capital units) that would restore the balance in productivity is just $G /\left(1-S^{T^{\prime}} f_{22}^{s} G\right)$. This tends to reduce the original impact of $E$ on the productivity of capital (indeed for a small country the original impact is completely eliminated). 
This effect is the origin of the strategic behavior of the Northern government when setting its environmental policies ${ }^{8}$ Indeed, if we take into account interest payments, as well as equations (1), and (2), the first order conditions for optimal environmental indices, that is, for maximization of (5) and (6), the latter for exogenous $r$, are respectively,

$$
U_{2}^{s} f_{3}^{s}+1=0
$$

and

$$
U_{2}^{n}\left[f_{3}^{n}+\frac{d r}{d E^{n}}\left(S^{n}-k^{n}\right)\right]+1=0
$$

Compare these equations with equation (4) above. The difference in (8) is the second term in the parenthesis, this term gives rise to the incentives of the government to manipulate the interest rate so as to influence the revenues associated with capital exports. At least if the governments' objective functions are concave in the corresponding instruments, $E^{i}$, this implies that the Northern country has incentives to set lower environment standards (quality) so as to improve the returns on its capital exports.

The first order conditions above have an intuitive interpretation. When increasing the level of environmental quality in its country, government $i$ considers the positive, direct impact on utility, as measured by $u_{3}^{i}=1$, and the decrease in local output that the higher level of environmental quality produces, as measured by $U_{2}^{i} f_{3}^{i}$. These are the non-strategic incentives. However, on top of this, the Northern government has an incentive to manipulate the marginal productivity of capital, that is, the interest rate. Indeed, the government of country $n$, which is a net exporter of capital, will have an additional incentive to lower environmental quality, which improves the global productivity of capital, $(\mathrm{d} r) /\left(\mathrm{d} E^{n}\right)<0$, and therefore the price foreign borrowers pay for Northern capital. These strategic incentives are represented by the second term on the left hand side of (8).

\section{Does The South Become Dirtier?}

The question now is how this strategic distortion in the Northern environmental quality influences the Southern level $E^{s}$. Indeed, even if the Southern government cannot influence the interest rate in the international market, it can certainly influence the inflow of capital from abroad by manipulating the domestic productivity conditions with the environmental variable. To answer this question, we totally differentiate the first order condition for optimal $E^{s}$, with respect to both $r$, and $E^{s}$ to obtain

$$
\frac{\mathrm{d} E^{s}}{\mathrm{~d} r}=-\frac{f_{3}^{s}\left[-U_{21}^{s} S^{s^{\prime}}+U_{22}^{s}\left(\frac{\mathrm{d}(1+r) S^{s}}{\mathrm{~d} r}-k^{s}\right)\right]+U_{2}^{s} \frac{\mathrm{d} f_{3}^{s}}{\mathrm{~d} r}}{U_{22}^{s}\left(f_{3}^{s}\right)^{2}+U_{2}^{s} \frac{\mathrm{d} f_{3}^{s}}{\mathrm{~d} E^{s}}} .
$$

8 The strategic behavior of large capital exporting countries is well characterized in Rauscher (1997). However as we want to analyze the corresponding response of the South, we need to include the discussion here in the framework of our model for the sake of completeness. 
Equation (9) describes the effect induced on $E^{s}$ by a change in $r$. This effect can be seen as the change that would balance the level of $U_{2}^{s} f_{3}^{s}$ back to its level of -1 . Alternatively, it could be seen as how changes in the interest rate change the balance between value of the environment, and of period two consumption. If the terms meaning greater value of period two consumption dominate, then lower level of the environmental index will result.

The original change in $r$ implies an increase in savings by the consumer in the South. It reduces consumption in the first period, and this can increase or decrease the marginal utility of consumption in the second period. This is the first term in brackets in (9). If it reduces marginal utility of consumption in the second period ( $U_{21}^{s}$ negative) then it would clearly favour lower environmental quality (given that $f_{3}^{s} U_{21}^{s} S^{s^{\prime}}$ would be positive). If instead $U_{21}^{s}$ is positive then this term would favour an increase in environmental quality. On the other hand, these higher savings and interest rate imply higher revenue in the second period, and also lower value of second period consumption (measured by $\left.-f_{3}^{s} U_{22}^{s}\left(\mathrm{~d}(1+r) S^{s}\right) /(\mathrm{d} r)\right)$. These terms related to the increase in savings are the ones that could imply an increase in environmental quality.

However, the increase in the interest rate also lowers profits for the firm, which means lower revenue. This implies lower consumption in the second period, and an increase in the value of this consumption (this effect is represented by the term $f_{3}^{s} U_{22}^{s} k^{s}$ ).

If the country is small in initial resources (high capital imports), we expect this last effect to be larger that the ones associated to the increase in savings unless the responsiveness of savings to interest rates is extremely high. ${ }^{9}$ Then, the increase in the interest rate would reduce second period consumption, and this would increase the marginal utility of this consumption.

Finally, as the interest rate rises, and capital in the South decreases, the (negative) effect of the environmental index is reduced. That is, $f_{3}^{s}$ becomes larger

$$
\frac{\mathrm{d} f_{3}^{s}}{\mathrm{~d} r}=\frac{f_{32}^{s}}{f_{22}^{s}}
$$

These effects are the ones that appear in the numerator of equation (9). Except for this latter one, we expect these effects to be negative (since $f_{3}^{s}$ is negative). Thus, unless the productivity of capital is very responsive to the environmental variable, and very unresponsive to the level of capital itself, the effect of $r$ on $U_{2}^{s} f_{3}^{s}$ should be negative. How should $E^{s}$ change in order to compensate for this?. First, a change in $E^{s}$ reduces output in the second period, and then increases the marginal productivity of consumption in that period. However, the effect of $E^{s}$ on $f_{3}^{s}$ is less clear. The direct effect of $E^{s}, f_{33}^{s}$, could be (at least partially) compensated for by the reduction in capital that lower productivity induces,

$$
\frac{\mathrm{d} f_{3}^{s}}{\mathrm{~d} E^{s}}=f_{33}^{s}-\frac{\left(f_{32}^{s}\right)^{2}}{f_{22}^{s}} .
$$

9. If we analyze discrete changes in the interest rate, as would actually follow from strategic incentives by the North, this responsiveness is bounded by initial resources, and can then never be too high. 
These effects are the ones that appear in the denominator. Again, unless the productivity of capital is very responsive to the environmental variable in the South, and not very responsive to changes in the level of this capital, the denominator is negative. So, the environmental index has to be reduced in order to compensate for the higher interest rate, i.e., $\mathrm{d} E^{s} / \mathrm{d}(1+r)<0$. That is, the South will also reduce the environmental standards as a response to the lower standards set by the North. That is, their policies are strategic complements. The total effect is a global decrease in environmental quality, as the following proposition states.

PROPOSITION: For moderate values of $S^{s^{\prime}}, f_{22}^{s}$, and $f_{23}^{s}$, the strategic distortion that capital exports causes in the Northern environmental policies makes both the North and the South dirtier.

The South responds to the lower environmental quality in the North by also decreasing environmental quality so as to compensate for the capital flight from the South. We should consider it unlikely that a higher interest rate should induce a very high increase in savings in the South, so high as to increase the consumption in the second period in this capital importing country. Then, the only possible exceptions to the Proposition would require high responsiveness of the productivity of capital to the environmental variable and/or low responsiveness to the level of capital so that one of the following two cases, but not the other, would occur:

1) The increase in interest rate causes a steep decline in the level of capital in the South $\left(1 / f_{22}^{s}\right)$, which reduces the negative effect of the environmental quality on output drastically $\left(f_{23}^{s}\right)$.

2) Tougher environmental regulations reduce the level of domestic capital drastically $-\left(f_{23}^{s} / f_{22}^{s}\right)$, so the marginal effect of these regulations on output $\left(f_{3}^{s}\right)$ is lower for tougher regulations.

In these cases, environmental policies could be strategic substitutes, and then the South would set more stringent regulations on the environment as a response to the lenient policies of the North. However, in general we expect the policies to be strategic complements, and the South to respond with dirtier policies too.

\section{Conclusions}

We have presented a very stylized model of perfect competition with two regions, a North that is capital abundant, and a South that is not. The North has incentives to decrease the environmental quality below the autarky level in order to distort the price of capital exports. This is done through inducing scarcity of this capital via softer environmental conditions at home.

If the South consists of small countries with respect to the effect of their policies on international interest rate, their environmental decisions would be those corresponding to a non-strategic situation given the decisions of the North. However, under quite plausible conditions, they would respond to the lower environmental quality levels in the North, and the subsequent interest rate, by decreasing environmental quality. 
We have carried out the analysis under the assumption of no unemployment. Unemployment in the South would imply yet an additional incentive for Southern countries to relax their environmental regulations. The effect of the price distortion induced by Northern policies (more expensive capital) would only enforce this new incentive.

We have also assumed that pollution is local, rather than transboundary. Transboundary pollution could be trivially accomodated in our damage function. The North would see its incentives for lenient regulations tempered. Indeed, a more expensive capital now induces the South to pollute more, thus negatively affecting the Northern welfare. However, our main insight would carry over to this case: as far as the North indeed distorts the interest rate upwards the response we expect from the South is to lower environmental protection.

Finally, we have assumed away any income effects, such as those discussed in Copeland and Taylor (1997). Again, as long as environmental quality is a normal good, income effects would work in the direction of reducing the incentives for the North to lower the environmental protection. But, once again, this does not change the direction of the response of the South to more expensive capital.

\section{References}

Barbera, A., and V. McConnell (1986). Effects of Pollution Control on Industry Productivity: A Factor Demand Approach. Journal of Industrial Economics, 35, pp. 161-172.

Barrett, S. (1994). Strategic Environmental Policy, and International Trade. Journal of Public Economics, 54, pp. 325-38.

Beladi, H., C. Chao, and R. Frasca (1999). Foreign Investment, and Environmental Regulations in LDCs. Resource and Energy Economics, 21, pp. 191-199.

Burguet, R., and J. Sempere (1998). Does Freer Imply Weaker, and Weaker too Weak?: Trade Incentives, and Environmental Regulation. Mimeo. Institute for Economic Analysis, and El Colegio de México.

Copeland, B., and M. Taylor (1994). North-South Trade, and the Environment. Quarterly Journal of Economics, 438, pp. 755-87.

Copeland, B., and M. Taylor (1995). Trade, and Transboundary Pollution. American Economic Review, 85, pp. 16-737.

Copeland, B., and M. Taylor (1997). A Simple Model of Trade, Capital Mobility, and The Environment. National Bureau of Economic Research. Working Paper No. 5898.

Gollop, F., and M. Roberts (1983). Environmental Regulations, and Productivity Growth: The Case of Fossil-Fueled Electric Generation. Journal of Political Economy, 91, pp. 654-674.

Gray, W., and R. Shadbegian (1995). Pollution Abatement Costs, Regulation, and Plant Level Productivity. National Bureau of Economic Research. Working Paper No. 4994.

Gray, W. (1987). The Cost of Regulation: OSHA, EPA, and The Productivity Slowdown. American Economic Review, 77, pp. 998-1006.

Hoel, M. (1997). Coordination of Environmental Policy for Transboundary Environmental Problems?. Journal of Public Economics, 66, pp. 199-224.

Kennedy, P. (1994). Equilibrium Pollution Taxes in Open Economies with Imperfect Competition. Journal of Environmental Economics and Management, 27, pp. 49-63.

Ludema, R., and I. Wooton (1994). Cross-Border Externalities, and Trade Liberalization: The Strategic Control of Pollution. Canadian Journal of Economics, 27, pp. 950-966.

Markusen, J. (1975). Control of International Pollution, and Common Resources. Quarterly Journal of Economics, 357, pp. 619-632. 
Markusen, J., E. Morey, and N. Olewiler (1995). Competition in Regional Environmental Policies when Plant Locations are Endogenous. Journal of Public Economics, 56, pp. 55-77.

Rauscher, M. (1997). International Trade, Factor Movements, and The Environment. Oxford Clarendon.

Ulph, A. (1996). Strategic Environmental Policy, International Trade, and The Single European Market. In Brander, J., H. Folmer, and T. Ulen (Eds.). Environmental Policy with Political, and Economic Integration: The European Union, and The United States. Edward Elgar Publishing Limited, Uk, pp. 235-56. 